Article

\title{
Bioactivity of Fucoidan as an Antimicrobial Agent in a New Functional Beverage
}

\author{
Gabriela del Carmen Poveda-Castillo ${ }^{1}$, Dolores Rodrigo ${ }^{1}$, Antonio Martínez ${ }^{1}$ and \\ Maria Consuelo Pina-Pérez ${ }^{2, *}$ \\ 1 Departamento de Conservación y Calidad, Instituto de Agroquimica y Tecnologia de Alimentos, \\ Avda. Agustin Escardino 7, Paterna, 46022 Valencia, Spain; gabrielapoveda22@gmail.com (G.d.C.P.-C.); \\ lolesra@iata.csic.es (D.R.); amartinez@iata.csic.es (A.M.) \\ 2 Department of Food Natural Products, Institute of Life Technologies, HES.SO VALAIS-WALLIS, \\ Rue du Rawil 64, 1950 Sion, Switzerland \\ * Correspondence: maria.pinaperez@hevs.ch; Tel.: +41-(0)27-606-89-11
}

Received: 10 July 2018; Accepted: 29 August 2018; Published: 1 September 2018

\begin{abstract}
Seaweeds are a sustainable source of novel functional ingredients with applicability in pharmaceutics, biotechnology, and food science. The bioactivity of most of these marine compounds has scarcely been studied. The present study overviews the bioactivity of the polysaccharide fucoidan derived from Fucus vesiculosus brown algae as an antimicrobial agent against Listeria monocytogenes and Salmonella enterica serovar Typhimurium. The results obtained in vitro in reference medium reveal a bacteriostatic and bactericidal effect of fucoidan against both pathogens, this bioactivity being significantly dependent ( $p$-value $\leq 0.05$ ) on the concentration, $5-1000 \mu \mathrm{g} / \mathrm{mL}$, temperature, $8-37^{\circ} \mathrm{C}$, and exposure time, $0-12$ days. The results were validated in the formulation of a new functional pasteurized apple beverage to be commercialized under refrigeration. Fucoidan added at $25-100 \mu \mathrm{g} / \mathrm{mL}$ was highly effective against both pathogens. These results increase knowledge for the future formulation of new functional beverages that include marine compounds (high content in fibre, high content in protein; prebiotic and antioxidant properties), additionally revealing antimicrobial potential.
\end{abstract}

Keywords: Fucoidan; seaweed; Fucus vesiculosus; Listeria monocytogenes; Salmonella typhimurium; antimicrobials

\section{Introduction}

Natural antimicrobials of animal, vegetable, and marine origin have gained importance in recent years. Specifically, marine organisms have emerged as a sustainable source of products with high applicability in industry.

Seaweeds are divided into three groups of macroalgae, red (Rhodophyta), brown (Phaeophyta), and green (Chlorophyta), depending on their nutrient and chemical composition. In particular, brown seaweeds (e.g., Laminaria digitata, Ascophyllum nodosum, Fucus vesiculosus, Macrocystis pyrifera, Sargassum fusiforme, Undaria pinnatifida) have a long history of consumption in Japan, Korea, and south-east Asian countries [1,2]. Brown algae have been consumed since ancient times in China, and their benefits have been associated with one of the highest ratios of longest-living people in the world (34 centenarians for every 100,000 inhabitants) [3]. Owing to the highly nutritious composition of these organisms, with their high protein content, high concentration of polysaccharides, natural richness in minerals, polyunsaturated fatty acids (PUFA), and vitamins; and their high content of bioactive molecules, brown algae are being studied in depth as edible vegetables to be distributed to general consumers, both as raw products and as ingredients obtained by extracting specific compounds [4]. 
The search for novel ingredients to increase the healthy potential of ready-to-eat (RTE) products is increasing in the food market. Sustainable ingredients that are capable of increasing the fibre content of the final product or improving the prebiotic qualities of these newly designed foods are now being investigated [5]. Moreover, the search for ways of increasing the protein content of formulations targeted at infants and the elderly is an additional stimulus for the formulation of new products $[3,6]$.

Specific bioactivities exerted by brown algae compounds place this group in the spotlight for the discovery of natural ingredients with anti-cancer potential, anti-inflammatory, antioxidant, and antimicrobial activities, and satiating, prebiotic, and anti-obesity properties [7-11].

Given the need to find effective alternative antimicrobials against antibiotic-resistant bacteria, many components of brown algae have been investigated. Nowadays, phlorotannins, PUFA, polysaccharides, proteins, and peptides are presented as effective antimicrobial agents against Gram-positive and Gram-negative bacteria, yeasts, and even viruses [11-13].

Sulfated polysaccharides (e.g., alginic acids, laminarins, and fucoidans) in brown algae, representing $5-40 \%$ of the dry weight of the raw material, have been successfully explored for pharmaceutical and dietary applications [14]. Fucoidan is a term used for fucose-rich polysaccharides found in the fibrillar cell walls and intercellular spaces of brown seaweeds [10]. These sulfated fucose polysaccharides are generally built of a backbone of $(1 \rightarrow 3)$ - and $(1 \rightarrow 4)$-linked $\alpha$-l-fucopyranose residues (from 100 to $1600 \mathrm{kDa}$ molecular weight). The antibacterial activity of fucoidan has been demonstrated against some clinical pathogens, such as Staphylococcus aureus, Escherichia coli, and Helicobacter pylori $[15,16]$.

Glycoprotein receptors present on the cell surface of polysaccharides appear to be responsible for the antibacterial action of fucoidan, owing to their ability to bind with compounds in the bacterial cell wall, cytoplasmic membrane, and DNA [13,17]. In spite of fucoidan's promising antimicrobial potential, its antibacterial capability against foodborne pathogens has scarcely been assessed [18].

The aim of the present study is to evaluate the effectiveness of fucoidan from Fucus vesiculosus as a preservative agent in a pasteurized apple juice-based beverage to be marketed under refrigeration. To achieve this purpose, firstly, several fucoidan concentrations and incubation conditions (temperature and exposure time) will be assayed in reference medium against two of the most important foodborne pathogens, Listeria monocytogenes and Salmonella enterica serovar Typhimurium [19,20]. The final objective is to contribute to increasing current knowledge in the validation of the applicability of this ingredient with functional (prebiotic and antioxidant) and technological (preservative) properties in food.

\section{Material and Methods}

\subsection{Listeria Monocytogenes}

The present study was carried out using the strain Listeria monocytogenes CECT 911 provided by the Spanish Culture Type Collection (CECT, PATERNA, Spain). The lyophilized culture was revived according to the instructions provided by the CECT. Briefly, the lyophilized bacterial content provided in a capsule was diluted in $0.2 \mathrm{~mL}$ of Tryptic Soy Broth (TSB) (Scharlab, Barcelona, Spain) and afterwards transferred to a sterile flask containing $10 \mathrm{~mL}$ of TSB. The flask was incubated at $37{ }^{\circ} \mathrm{C}$ for $30 \mathrm{~min}$. The culture was then incubated in a flask of $400 \mathrm{~mL}$ sterile TSB for $16 \mathrm{~h}$ at $37^{\circ} \mathrm{C}$, with constant stirring (200 rpm), until the stationary phase was obtained. Cells were recovered by two centrifugation steps $\left(4000 \times g, 15 \mathrm{~min}, 4^{\circ} \mathrm{C}\right)$, with removal of the supernatant each time. Recovered cells were resuspended in sterile TSB supplemented with $20 \%$ glycerol [1:1]. A stock culture was prepared and maintained frozen at $-80^{\circ} \mathrm{C}$ in $2 \mathrm{~mL}$ cryovials. The final concentration of the stock was $5 \pm 0.8 \times 10^{9} \mathrm{CFU} / \mathrm{mL}$. 


\subsection{Salmonella Enterica Serovar Typhimurium}

A pure culture of $S$. typhimurium (CECT 443) was provided freeze-dried by the Spanish Type Culture Collection. After rehydration in $10 \mathrm{~mL}$ of Tryptic Soy Broth (TSB) (Scharlab Chemie, Barcelona, Spain), the culture was transferred to $500 \mathrm{~mL}$ of TSB and incubated at $37^{\circ} \mathrm{C}$ with continuous shaking (200 rpm) for $14 \mathrm{~h}$ to obtain cells in a stationary growth stage according to the method previously described by Saucedo-Reyes et al. [21]. The cells were centrifuged twice at $4000 \times \mathrm{g}$ at $4{ }^{\circ} \mathrm{C}$ for $15 \mathrm{~min}$ and then resuspended in TSB. After centrifugation, the cells were recovered and resuspended in $20 \mathrm{~mL}$ of TSB with $20 \%$ glycerol. The bacterial suspension was dispensed in $2 \mathrm{~mL}$ vials with a final concentration of $10^{8} \mathrm{CFU} / \mathrm{mL}$. The $2 \mathrm{~mL}$ samples were immediately frozen and stored at $-80^{\circ} \mathrm{C}$ until needed for the antimicrobial studies.

\subsection{Fucoidan Suspension Preparation}

Fucoidan from the Fucus vesiculosus species belonging to the Phaeophyceae group (brown algae) was provided by Sigma-Aldrich (Sigma-Aldrich Chemie GmbH, Buchs, Switzerland) as an odourless white powdered product with purity $\geq 95 \%$ (reference number F8190-500).

Suspensions containing fucoidan at different concentrations were prepared using Mueller Hinton Broth (MHB) (Scharlab, Barcelona, Spain) as reference medium. A stock solution was prepared containing $5000 \mu \mathrm{g} / \mathrm{mL}$ of fucoidan in MHB. The suspension was sterilized by filtration (Minisart $0.20 \mu \mathrm{m}$ filters; reference 16534-K) (Sigma-Aldrich Inc., St. Louis, USA). The stock solution was divided into aliquots and maintained at $-20{ }^{\circ} \mathrm{C}$ to guarantee the homogeneity of the preparations in independent work sessions. Tubes containing 5, 10, 25, 50,100, 200, and $1000 \mu \mathrm{g} / \mathrm{mL}$ of fucoidan were prepared in sterile MHB in triplicate. Tubes not supplemented with fucoidan, containing only MHB, were also prepared.

\subsection{Inoculum and Incubation Conditions}

The suspensions supplemented/not supplemented with fucoidan were inoculated with L. monocytogenes and S. typhimurium at a final concentration of $4.5 \times 10^{4} \mathrm{CFU} / \mathrm{mL}$.

To monitor possible side contaminations during the assay period, a battery of non-inoculated tubes (blank samples) was also prepared, supplemented/not supplemented with fucoidan. Suspensions were incubated at the optimum growth temperature of the bacteria, $37^{\circ} \mathrm{C}$, and also at $8{ }^{\circ} \mathrm{C}$, a slight abuse refrigeration temperature (worst scenario corresponding to a cold chain breakage) with high risk for pasteurized products. The incubation period was 7 days at $37^{\circ} \mathrm{C}$, and 12 days at $8^{\circ} \mathrm{C}$.

\subsection{Growth Kinetic Study under Fucoidan Exposure}

The growth behaviour of the bacteria was recorded by means of spectrophotometric measurements $\left(\mathrm{OD}_{550 \mathrm{~nm}}\right)$ and plate count [7]. Aliquots were taken regularly, both from samples incubated at $37^{\circ} \mathrm{C}(0$, $1,2,3,5,7$ days) and from samples incubated at $8^{\circ} \mathrm{C}(0,1,2,3,5,7,12$ days), and spectrophotometric and $\mathrm{CFU} / \mathrm{mL}$ quantitative values were recorded. Blank samples were used as control in the OD measurements. The suspensions were monitored during the complete incubation period to determine the stability of each of the formulated matrices under the conditions studied.

Serial dilutions in Buffered Peptone Water (BPW) (Scharlab, Barcelona, Spain) (1:1000 (w/v)) were made from suspensions during the period studied, and seeded on Tryptic Soy Agar (TSA) (Scharlab S.A., Barcelona, Spain) plates in duplicate. The plates were incubated at $37^{\circ} \mathrm{C}$ for $48 \mathrm{~h}$ prior to the bacterial count $(\mathrm{CFU} / \mathrm{mL})$. All the assays were carried out in triplicate on three separate days.

The growth/inhibition results obtained for L. monocytogenes and S. typhimurium under exposure to fucoidan were represented as the decimal $\log$ of viable cells $\left(\log _{10}\left(\mathrm{~N} f / \mathrm{N}_{0}\right), \mathrm{N} f\right.$ being the number of viable cells at each point in time in $\mathrm{CFU} / \mathrm{mL}$, and $\mathrm{N}_{0}$ the initial CFU $/ \mathrm{mL}$ at $t=0$ days) versus the incubation time (days), to determine the bacteriostatic and/or bactericidal effect of this compound. 


\subsection{Formulation of a New Functional Apple Juice Beverage}

A new prebiotic apple juice beverage $(\mathrm{pH}=4.3)$ was formulated, including fucoidan at several concentrations, to validate the effectiveness of fucoidan in a real food matrix. Suspensions of fucoidan at 25,100 , and $1000 \mu \mathrm{g} / \mathrm{mL}$ were prepared in UHT apple juice to determine the effectiveness of fucoidan in this simple substrate. Supplemented/non-supplemented matrices were inoculated with L. monocytogenes and S. typhimurium to obtain a final concentration of $5 \times 10^{4} \mathrm{CFU} / \mathrm{mL}$. The non-supplemented apple juice was considered as the control sample. The non-supplemented and non-inoculated apple juice was considered as the blank sample.

\subsection{Statistical Analysis of Data}

An ANOVA analysis was carried out to determine statistically significant differences ( $p$-value $\leq 0.05)$ between the growth/inhibition/reduction of bacterial levels under the conditions studied, taking into account the variables included in the present study: fucoidan concentration $(\mu \mathrm{g} / \mathrm{mL})$, temperature $\left({ }^{\circ} \mathrm{C}\right)$ and exposure time (days). All the statistical analyses were carried out using Statgraphics Centurion XV software (Statpoint Technologies Inc., Warrenton, VA, USA).

\section{Results}

\subsection{Antimicrobial Potential of Fucoidan against L. monocytogenes}

Figure 1 presents the growth kinetic results from the incubation studies at 37 and $8{ }^{\circ} \mathrm{C}$ in reference MHB medium supplemented/not supplemented with fucoidan. As can be seen graphically, at the slight abuse refrigeration temperature L. monocytogenes was able to grow to a maximum of $1.06 \pm 0.15$ $\log$ cycle in MHB, during the incubation period of 12 days.

The addition of fucoidan at low concentrations in the range $5-25 \mu \mathrm{g} / \mathrm{mL}$ had no bacteriostatic or bactericidal effect in the control of this pathogen. When the concentration of fucoidan was increased to $50 \mu \mathrm{g} / \mathrm{mL}$, a bacteriostatic effect was exerted close to $0.75 \log$ cycles $\left(8{ }^{\circ} \mathrm{C}, 7\right.$ days). Higher $100-1000 \mu \mathrm{g} / \mathrm{mL}$ fucoidan concentrations were bactericidal (0.66-1.12 log cycles reduction) after 12 days of cell exposure at $8{ }^{\circ} \mathrm{C}$.

At the optimum growth temperature of the bacterium, fucoidan showed both a bacteriostatic and a bactericidal effect against L. monocytogenes, depending on the concentration added ( $p$-value $\leq 0.05$ ) and the exposure time considered ( $p$-value $\leq 0.05$ ). Fucoidan concentrations of 5,25 , and $50 \mu \mathrm{g} / \mathrm{mL}$ showed a bacteriostatic effect against L. monocytogenes after 5 days of incubation, inhibiting growth of this pathogen by up to $1.62 \pm 0.08 \mathrm{log}$ cycle with respect to the control. When the exposure time increased, during incubation for 5 to 7 days at $37^{\circ} \mathrm{C}$, the antimicrobial potential of the lowest fucoidan concentrations increased significantly ( $p$-value $\leq 0.05$ ). The $5 \mu \mathrm{g} / \mathrm{mL}$ fucoidan concentration was effective in inhibiting the growth of the pathogen to a maximum of $1.95 \pm 0.06 \log$ cycles after 7 days of exposure. Concentrations in the range $25-50 \mu \mathrm{g} / \mathrm{mL}$ became bactericidal, reducing the initial bacterial levels by nearly $0.40 \log$ cycles, after 7 days of incubation at $37^{\circ} \mathrm{C}$.

The highest concentrations of fucoidan, 100, 200, and $1000 \mu \mathrm{g} / \mathrm{mL}$, showed a bactericidal effect against L. monocytogenes even after only $24 \mathrm{~h}$ of incubation at $37^{\circ} \mathrm{C}$. However, no significant differences were observed in the bactericidal effect attributable to fucoidan in the concentration range studied $100-1000 \mu \mathrm{g} / \mathrm{mL}$. Moreover, no significant increase in the bactericidal effect due to an increase in exposure time was observed in this concentration range (from $0.51 \mathrm{log}$ cycles bacterial reduction after $24 \mathrm{~h}$ of incubation to $0.62 \log$ cycles reduction after 7 days of incubation).

Previous studies carried out by Lee et al. [22] attributed a high antimicrobial potential to fucoidan against Gram-positive and Gram-negative bacteria commonly present in the oral cavity (Streptococcus mutans, Fusobacterium nucleatum, and Porphyromonas gingivalis, among others). The bacteriostatic potential of fucoidan against these bacteria was in the range of $150-500 \mu \mathrm{g} / \mathrm{mL}$. Fucoidan showed a bactericidal effect against oral cavity bacteria in the range of 250-1000 $\mu \mathrm{g} / \mathrm{mL}$. Similar results were reported by Choi et al. [12], with MIC and MBC equal to $128 \mu \mathrm{g} / \mathrm{mL}$ and 256-512 $\mu \mathrm{g} / \mathrm{mL}$, respectively, 
against several strains of $S$. aureus (Gram-positive). According to our results, a higher antimicrobial potential could be attributed to fucoidan derived from Fucus vesiculosus against the Gram-positive foodborne pathogen L. monocytogenes, the MIC at $37^{\circ} \mathrm{C}$ being $5 \mu \mathrm{g} / \mathrm{mL}$, and the $\mathrm{MBC}$ value $100 \mu \mathrm{g} / \mathrm{mL}$ at the same incubation temperature (see Table 1 ).

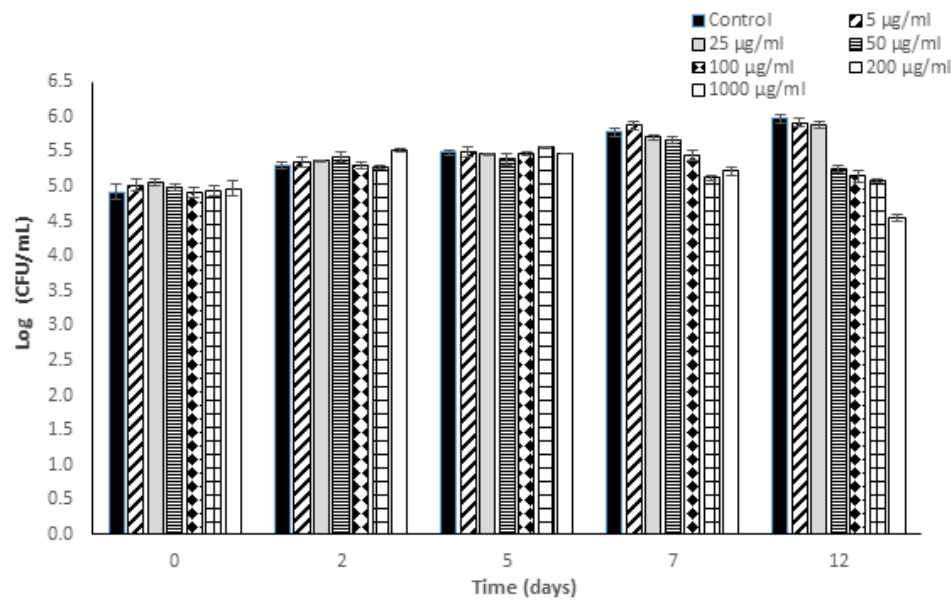

(A)

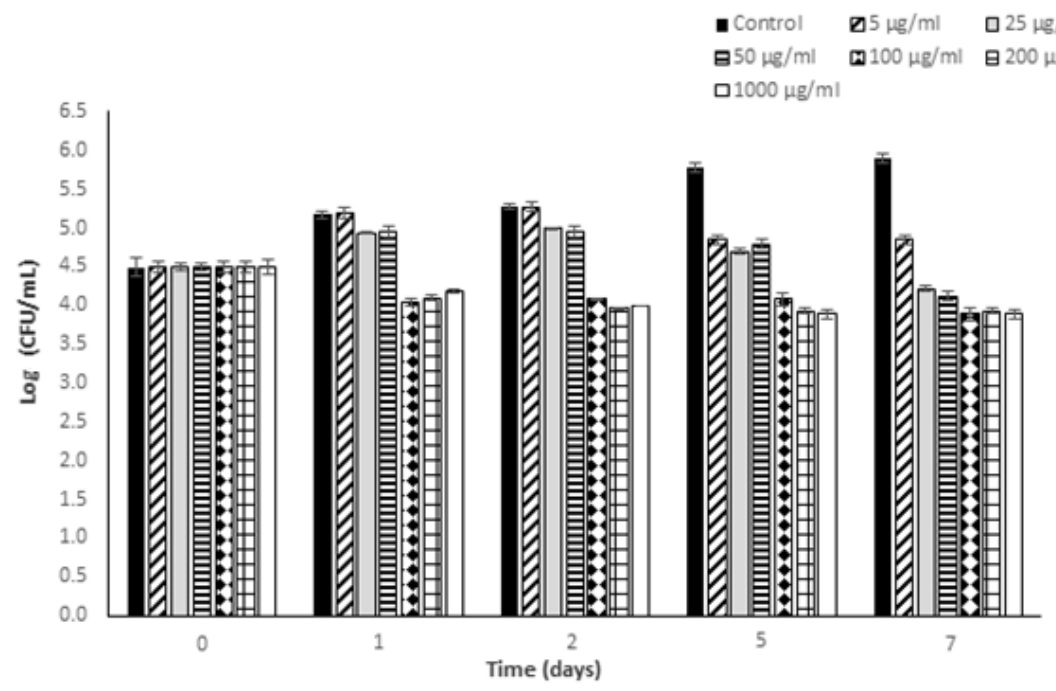

(B)

Figure 1. Kinetic results $(\log (\mathrm{CFU} / \mathrm{mL})$ versus time (days)) obtained in the determination of the in vitro antimicrobial potential of fucoidan against Listeria monocytogenes in reference medium, Mueller Hinton Broth (MHB). (A) $8{ }^{\circ} \mathrm{C}$ (12 days); (B) $37^{\circ} \mathrm{C}$ (7 days). 
Table 1. Fucoidan bacteriostatic and bactericidal potential against Listeria monocytogenes and Salmonella typhimurium in reference medium and in an apple juice-based beverage.

\begin{tabular}{|c|c|c|c|c|c|c|}
\hline \multirow[b]{3}{*}{ Substrates } & \multicolumn{6}{|c|}{ Temperature } \\
\hline & \multicolumn{3}{|c|}{$37^{\circ} \mathrm{C}$} & \multicolumn{3}{|c|}{$8^{\circ} \mathrm{C}$} \\
\hline & $\mu \mathrm{g} / \mathrm{mL}$ & Exposure time (days) & $\log _{10}$ cycles & $\mu \mathrm{g} / \mathrm{mL}$ & Exposure time (days) & Log cycles \\
\hline \multicolumn{7}{|c|}{ Listeria monocytogenes } \\
\hline \multicolumn{7}{|c|}{ Mueller Hinton Broth (MHB) } \\
\hline MIC & 5 & 5 & $1.55 \pm 0.04$ & 100 & 7 & $0.83 \pm 0.08$ \\
\hline MBC & 100 & 1 & $0.61 \pm 0.03$ & 50 & 12 & $0.89 \pm 0.13$ \\
\hline Apple juice & $\mu \mathrm{g} / \mathrm{mL}$ & Exposure time (days) & $\log _{10}$ cycles & $\mu \mathrm{g} / \mathrm{mL}$ & Exposure time (days) & Log cycles \\
\hline MIC & - & - & - & - & - & - \\
\hline MBC & - & - & - & 1000 & 12 & $0.70 \pm 0.06$ \\
\hline \multicolumn{7}{|c|}{ Salmonella typhimurium } \\
\hline \multicolumn{7}{|c|}{ Mueller Hinton Broth (MHB) } \\
\hline MIC & 1000 & 7 & $1.08 \pm 0.23$ & - & - & - \\
\hline MBC & - & - & - & 10 & 2 & $1.25 \pm 0.15$ \\
\hline Apple juice & $\mu \mathrm{g} / \mathrm{mL}$ & Exposure time (days) & $\log _{10}$ cycles & $\mu \mathrm{g} / \mathrm{mL}$ & Exposure time (days) & Log cycles \\
\hline MIC & - & - & - & - & - & - \\
\hline MBC & - & - & - & 25 & 2 & $1.52 \pm 0.08$ \\
\hline
\end{tabular}

MIC: Minimum inhibitory concentration ( $\mu \mathrm{g} / \mathrm{mL}) ;$ MBC: Minimum bactericidal concentration $(\mu \mathrm{g} / \mathrm{mL})$. 


\subsection{Antimicrobial Potential of Fucoidan against S. typhimurium}

The results of $S$. typhimurium growth inhibition and inactivation due to the effect of fucoidan are presented in Figure 2. As can be seen graphically, at low incubation temperature fucoidan concentrations in the range $5-1000 \mu \mathrm{g} / \mathrm{mL}$ were all effective in inhibiting bacterial growth, and even more in inactivating $S$. typhimurium, depending on the fucoidan concentration applied and the exposure time considered ( $p$-value $\leq 0.05)$.

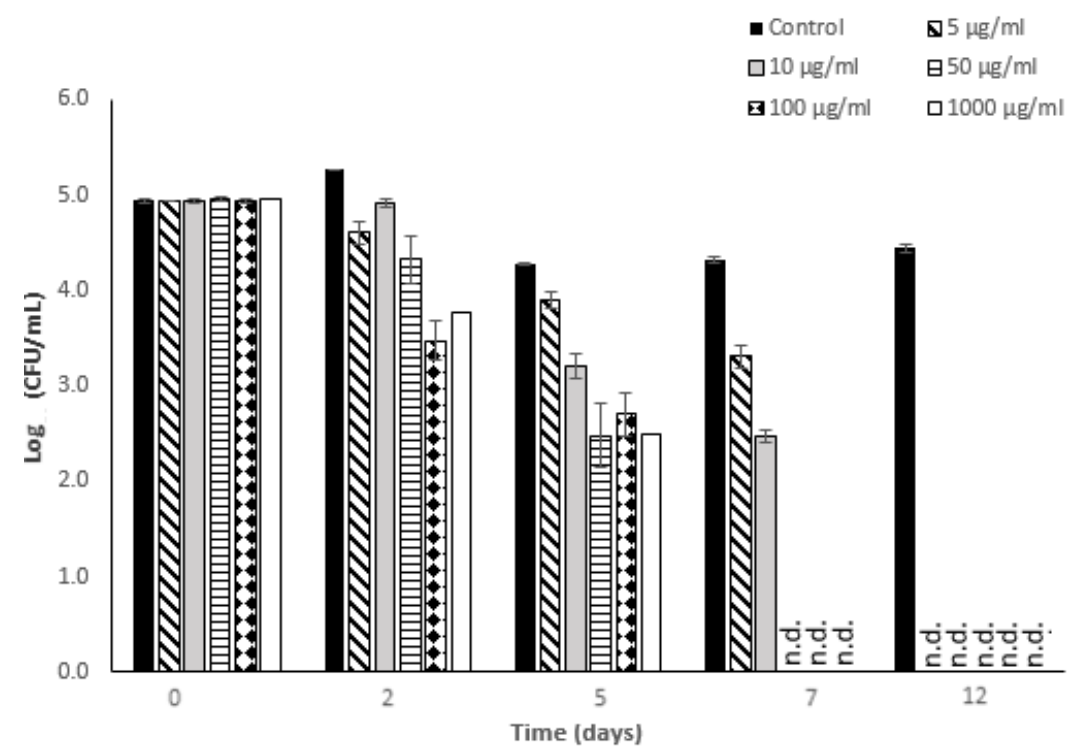

(A)

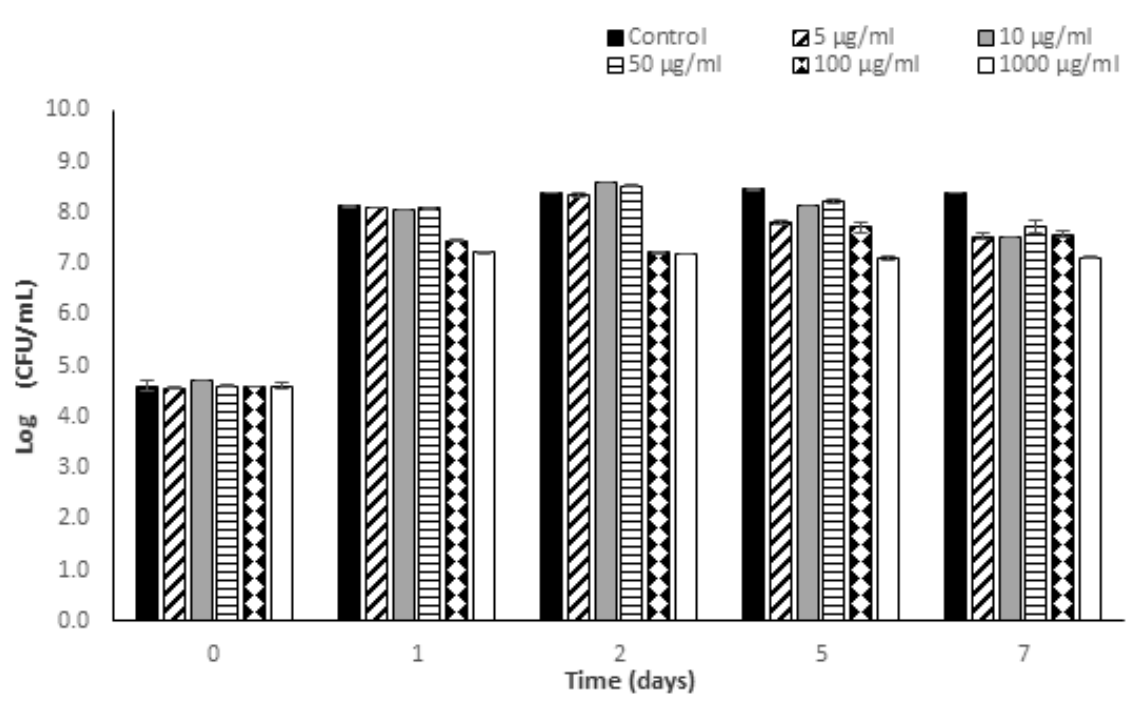

(B)

Figure 2. Kinetic results $(\log (\mathrm{CFU} / \mathrm{mL})$ versus time (days)) obtained in the determination of the in vitro antimicrobial potential of fucoidan against Salmonella typhimurium in reference medium, Mueller Hinton Broth (MHB). (A) $8{ }^{\circ} \mathrm{C}$ (12 days); (B) $37^{\circ} \mathrm{C}$ (7 days). Values below the detection limit are shown as not detected (n.d.).

In the non-supplemented MHB control medium, S. typhimurium was unable to grow at $8{ }^{\circ} \mathrm{C}$, and the initially inoculated levels decreased progressively during the refrigeration period $(0.50 \mathrm{log}$ cycles after 7 days). The lowest concentration of fucoidan, $5 \mu \mathrm{g} / \mathrm{mL}$, showed a bactericidal effect 
close to $1 \log _{10}$ cycle against $S$. typhimurium after only $48 \mathrm{~h}$ of refrigerated incubation. This effect increased as the exposure time continued, reaching a maximum reduction of $1.64 \mathrm{log}$ cycles after 5 days of exposure at this temperature. Fucoidan added at a concentration of $10 \mu \mathrm{g} / \mathrm{mL}$ reduced the $S$. typhimurium counts by nearly $1.84 \mathrm{log}$ cycles after $48 \mathrm{~h}$ of refrigerated exposure, achieving bactericidal effects close to $2.50 \log _{10}$ cycles after only 5 days of incubation at this temperature. Fucoidan concentrations in the range $5-10 \mu \mathrm{g} / \mathrm{mL}$ were effective in reducing the initial S. typhimurium counts to undetectable levels after 7 days of refrigerated incubation, which corresponds to a significant bactericidal effect close to $5 \log$ cycles. Fucoidan concentrations in the range $50-1000 \mu \mathrm{g} / \mathrm{mL}$ revealed a higher antimicrobial potential against this Gram-negative pathogen. Bacterial reductions in the range $0.65-1.5 \log$ cycles were achieved after only $24 \mathrm{~h}$ of refrigerated incubation in MHB medium supplemented with $50-1000 \mu \mathrm{g} / \mathrm{mL}$ of fucoidan (see Figure 2).

After 5 days of incubation there was a reduction of $2.5 \mathrm{log}$ cycles owing to exposure to $50-1000 \mu \mathrm{g} / \mathrm{mL}$ of fucoidan, and after 7 days of incubation in these supplemented matrices the S. typhimurium initial counts were reduced completely.

At the optimum growth temperature of the bacterium, $37^{\circ} \mathrm{C}$, fucoidan derived from Fucus vesiculosus showed a bacteriostatic effect, slowing down the growth rate of the bacterium and, consequently, the final levels during incubation, in comparison with the S. typhimurium counts observed in MHB control medium. Fucoidan concentrations in the range $5-50 \mu \mathrm{g} / \mathrm{mL}$ revealed a maximum bacteriostatic potential corresponding to $0.80 \mathrm{log}$ cycles of bacterial growth inhibition after 7 days of incubation at $37^{\circ} \mathrm{C}$. The higher the fucoidan concentration added to the medium, the higher the bacteriostatic effect ( $p$-value $\leq 0.05$ ) exerted by this bioactive compound. Suspensions of fucoidan in the range $100-1000 \mu \mathrm{g} / \mathrm{mL}$ were effective in inhibiting S. typhimurium growth by 1.08 to 1.22 log cycle, even in the first hours of exposure (24-48 h). During the incubation period, the longer the exposure time, the greater the effectiveness of $1000 \mu \mathrm{g} / \mathrm{mL}$ as a bacteriostatic agent ( $p$-value $\leq 0.05$ ), inhibiting bacterial growth by a maximum of $1.37 \pm 0.28 \mathrm{log}$ cycles in comparison to the growth observed in the control suspensions (MHB without fucoidan supplementation).

It can be concluded that the antimicrobial potential of fucoidan against $S$. typhimurium is significantly influenced by the variables studied (fucoidan concentration, incubation temperature, and exposure time) ( $p$-value $\leq 0.05)$, affecting the antimicrobial effectiveness of this compound. However, no significant increase in the antimicrobial capability of fucoidan was detected when the concentration added was increased from 100 to $1000 \mu \mathrm{g} / \mathrm{mL}$.

\subsection{Effectiveness of Fucoidan Derived from Fucus Vesiculosus against L. monocytogenes and S. typhimurium in a Newly Formulated Apple Juice Beverage}

Given the observed bacteriostatic and bactericidal potential of fucoidan against L. monocytogenes and S. typhimurium in reference medium, the effectiveness of this compound was assessed in an apple juice-based beverage to determine the applicability of this ingredient to achieve functional (prebiotic and antioxidant) $[5,23]$ and technological (preservative) objectives. Fucoidan was included in the formulation of the new beverage at concentrations of 25, 100, and $1000 \mu \mathrm{g} / \mathrm{mL}$. Sterile UHT apple juice was used as a basic food matrix $(\mathrm{pH}=4.3)$. The suspensions studied were maintained under the most disadvantageous conditions: slight abuse refrigeration temperature, $8^{\circ} \mathrm{C}$, for 12 days.

Figure 3 shows the results of growth/no growth of the bacterium in the food substrate studied when exposed to fucoidan. As can be seen graphically, L. monocytogenes was unable to grow in apple juice during the incubation period, despite which it remained viable at levels close to the initially inoculated values. 


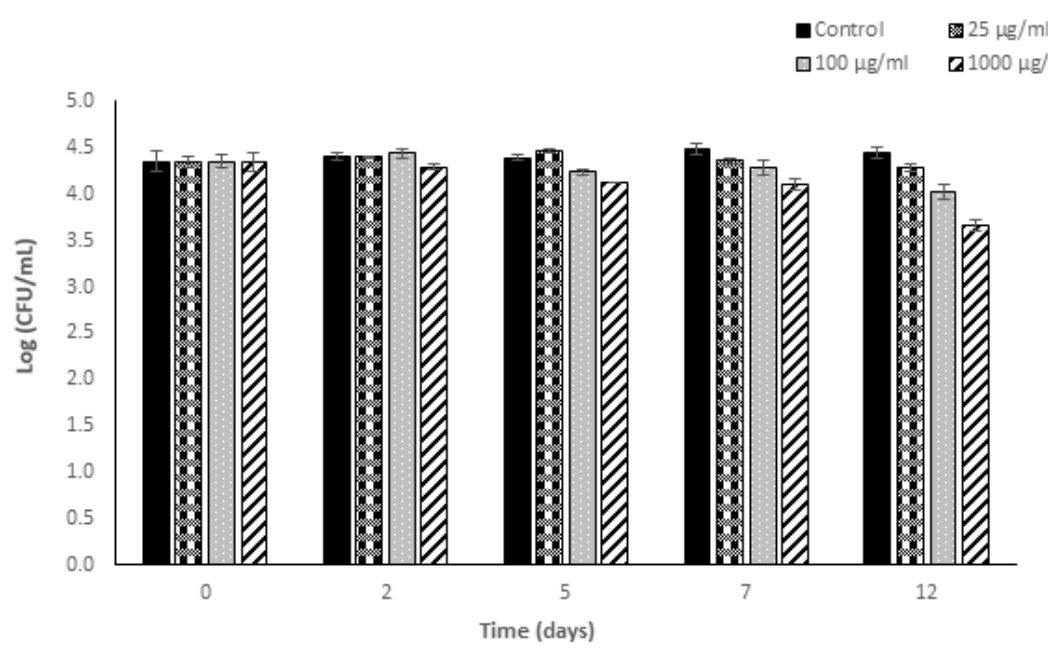

(A)

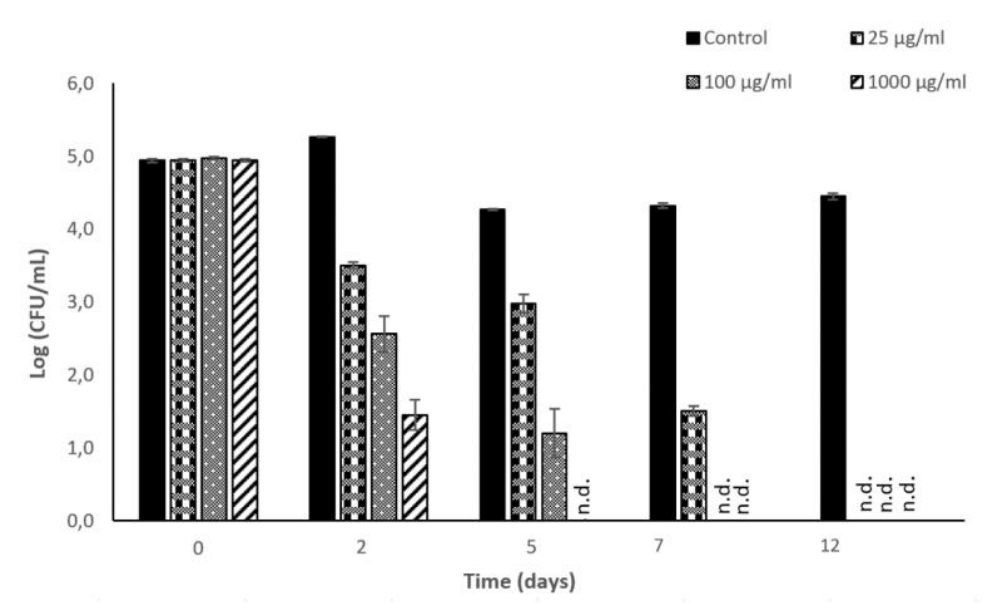

(B)

Figure 3. Antimicrobial potential of fucoidan from Fucus vesiculosus against Listeria monocytogenes (A) and Salmonella typhimurium (B) in a novel functional apple juice beverage stored at $8{ }^{\circ} \mathrm{C}$ for 12 days.

The addition of fucoidan at a concentration level of $25 \mu \mathrm{g} / \mathrm{mL}$ did not reveal any bactericidal effect against $L$. monocytogenes. Concentrations in the range $100-1000 \mu \mathrm{g} / \mathrm{mL}$ showed a low bactericidal effect; the longer the exposure time, the higher the bacterial reduction $(p$-value $\leq 0.05)$. Fucoidan added to apple juice at a concentration level of $100 \mu \mathrm{g} / \mathrm{mL}$ reduced the bacterial population by $0.40 \pm 0.02$ $\log$ cycles after 12 days of incubation. A fucoidan concentration of $1000 \mu \mathrm{g} / \mathrm{mL}$ proved effective in reducing the bacterial load in the food matrix to $0.70 \pm 0.01 \mathrm{log}$ cycles after an exposure time of 12 days at $8{ }^{\circ} \mathrm{C}$.

In the non-supplemented beverage, $S$. typhimurium was reduced slightly ( 1 log cycle) during the $8{ }^{\circ} \mathrm{C}$ incubation period, probably owing to two factors, the low $\mathrm{pH}$ and the low temperature conditions. However, after $48 \mathrm{~h}$ of incubation under these refrigerated acid conditions, the bacterial counts stabilized and remained in a viable-culturable stage until the final storage period. These results agree with those previously presented by Lee et al. [24] and Alvarez-Ordóñez et al. [25] regarding the acid-tolerance capability of $S$. typhimurium cells (CECT 443) in stationary phase incubated at different temperatures. With regard to the antimicrobial potential of fucoidan against $S$. typhimurium in this novel beverage, it was observed that all the concentrations studied were able to reduce the initially inoculated bacterial levels completely. The bactericidal potential of $25 \mu \mathrm{g} / \mathrm{mL}$ of fucoidan was close to 
$1.5 \log$ cycles after 2 days of exposure, and was close to 3.5. $\log$ cycles with $1000 \mu \mathrm{g} / \mathrm{mL}$ under the same incubation conditions ( 2 days, $8^{\circ} \mathrm{C}$ ). Significant differences in antimicrobial potential in the apple beverage were observed between the fucoidan concentrations of 100 and $1000 \mu \mathrm{g} / \mathrm{mL}$ ( $p$-value $\leq 0.05$ ); the higher the concentration added, the shorter the exposure time required to completely inactivate $S$. typhimurium in the food matrix. After 5 days of exposure incubated at $8^{\circ} \mathrm{C}$, the $1000 \mu \mathrm{g} / \mathrm{mL}$ fucoidan concentration was effective in reducing the S. typhimurium initial counts by 4 log cycles. Refrigerated incubation for 7 days was required to reduce the initially inoculated S. typhimurium bacterial levels completely when fucoidan was added at $100 \mu \mathrm{g} / \mathrm{mL}$, and $25 \mu \mathrm{g} / \mathrm{mL}$ was completely effective in reducing $S$. typhimurium below detectable levels after incubation for 12 days at $8{ }^{\circ} \mathrm{C}$.

Table 1 includes the fucoidan values that correspond to the minimum inhibitory concentrations (MIC) and minimum bactericidal concentrations (MBC) against the pathogens studied. From the results obtained, it can be concluded that $S$. typhimurium was more sensitive to the effect of fucoidan than L. monocytogenes.

L. monocytogenes is more sensitive to the antimicrobial effect of fucoidan at the optimum growth incubation temperature, and is more resistant to the antimicrobial bioactivity of fucoidan at refrigeration temperature. This behavioural response could be connected with the activation by the bacterium, under adverse external conditions (such as low temperatures or acidity, among others), of protective mechanisms that protect the bacterial cells against the effect of fucoidan [26]. Changes in membrane permeability could interfere with the effect of fucoidan, since one of the main actions of this compound is exerted at membrane surface level, by binding with specific receptors $[13,17]$. In this case, the ability of the bacterium to alter membrane permeability in order to increase tolerance to low temperatures could also be connected with interference with the activity of fucoidan under refrigerated conditions. Similar results were obtained by Belda-Galbis, Leufvén, Martínez, Rodrigo [27] and Belda-Galbis, Jiménez-Carretón, Pina-Pérez, Martínez, Rodrigo [28] regarding the antimicrobial potential of other natural compounds, açaí and carvacrol, against Listeria innocua, and they were also more effective at the optimum growth temperature of Listeria spp. $\left(37^{\circ} \mathrm{C}\right)$.

On the other hand, S. typhimurium is able to grow slightly at $37{ }^{\circ} \mathrm{C}$ even under the effect of fucoidan, and a concentration of $100 \mu \mathrm{g} / \mathrm{mL}$ is required to inhibit the bacterial growth by nearly 1 $\log$ cycle. However, at refrigeration temperature, the effect of fucoidan against this Gram-negative pathogen is very strong, with a MBC of $10 \mu \mathrm{g} / \mathrm{mL}$, reducing the initial inoculated bacterial counts by $1.25 \pm 0.15 \log$ cycles. In the apple beverage, $25 \mu \mathrm{g} / \mathrm{mL}$ is the MBC to achieve nearly $1 \log$ cycle of $S$. typhimurium reduction in only $48 \mathrm{~h}$ at $8^{\circ} \mathrm{C}$.

In the case of exposure of L. monocytogenes to fucoidan, concentration levels $\geq 50 \mu \mathrm{g} / \mathrm{mL}$ at $8{ }^{\circ} \mathrm{C}$ act only as growth control factors against this pathogen. From a comparison of the results of the effectiveness of fucoidan in $\mathrm{MHB}(\mathrm{pH}=6.8)$ and in apple juice $(\mathrm{pH}=4.3)$ at a refrigeration temperature of $8{ }^{\circ} \mathrm{C}$, it can be concluded that the antimicrobial potential of fucoidan against $L$. monocytogenes is higher in the food matrix than in the reference medium. This could be due to the combined effect of low-pH and addition of fucoidan, both acting as hurdles against proliferation of L. monocytogenes.

With regard to the antimicrobial potential of fucoidan against $S$. typhimurium, this compound also showed a greater antimicrobial effect when it was included in the formulation of the new acidic functional apple beverage. Inactivation levels close to $2 \log$ cycles were achieved after $48 \mathrm{~h}$ of bacterial exposure to a concentration of $100 \mu \mathrm{g} / \mathrm{mL}$ of fucoidan in the beverage, whereas 5 days of exposure were required in the reference medium to achieve the same level of microbial reduction.

From a technological point of view, the addition of fucoidan in a concentration range of $100-1000 \mu \mathrm{g} / \mathrm{mL}$ to this acidic apple-based beverage is presented as an effective measure for the control of $L$. monocytogenes, these levels being effective to guarantee reduction of the growing population by up to a maximum of nearly $1 \log _{10}$ cycle during the period of commercialization of this pasteurized product (12 days under refrigeration). Furthermore, the quality of the organoleptic properties of the apple juice remains intact after the addition of fucoidan $(25-1000 \mu \mathrm{g} / \mathrm{mL})$. To date, little information has been published about the physico-chemical changes induced in food matrices as a result of the 
addition of fucoidan extracts [29]. The physico-chemical and functional (antioxidant, gastroprotective, anti-inflammatory) properties of fucoidan depend on its molecular weight, structure, and concentration; and they vary depending on the source of the fucoidans, the harvest period, and the extraction methods [30]. Therefore, the impact of fucoidan extracts on the sensory properties of this novel food formulation will also depend on these specific features of fucoidan, and it should be optimized for the matrix in which the fucoidan is incorporated. The main physico-chemical changes in apple juice expected as a result of the addition of fucoidan could be increases in the lightness ( $\mathrm{L}$ value), viscosity (mPas), and turbidity of the liquid at high concentrations, accompanied by increases in the total soluble solids and the antioxidant potential of the juice [31].

Furthermore, from a functional point of view, according to the work of Hwang et al. [23], the use of both low and high molecular weight fucoidans at concentrations in the range of $50-100 \mu \mathrm{g} / \mathrm{mL}$ has a prebiotic potential, stimulating the growth of Bifidobacterium lactis in an in vitro model using Caco-2 cells. The adhesion of Bifidobacterium spp. cells to the gastrointestinal tract is increased by the intervention of fucoidans, which act as key determinants in the initialization of probiotic immunomodulatory activity [23]. Moreover, the antioxidant potential of fucoidans has been well demonstrated in vitro and in vivo, and fucoidan has even been incorporated in real food matrices, such as meat products [29].

\section{Conclusions}

The present study shows the effectiveness of fucoidan derived from Fucus vesiculosus brown algae as a natural antimicrobial against L. monocytogenes and S. typhimurium. This compound acts with a bacteriostatic and bactericidal effect at $37^{\circ} \mathrm{C}$ against L. monocytogenes, depending on the concentration added and the exposure time. At lower temperatures, close to refrigeration, when added at concentrations $\geq 100 \mu \mathrm{g} / \mathrm{mL}$, after 7 days of exposure fucoidan only exerted a bacteriostatic potential. Higher antimicrobial effectiveness of fucoidan was observed against $S$. typhimurium, with a $\mathrm{MBC}$ of $25 \mu \mathrm{g} / \mathrm{mL}$ in a novel apple-based beverage.

The results obtained in the present study open up new possibilities for research on the use of this natural compound as a sustainable bioactive ingredient to be added for the purpose of food preservation.

Author Contributions: Conceptualization, investigation, supervision and validation, M.C.P.-P.; Supervision and Funding Acquisition, A.M.; Investigation, G.d.C.P.-C.; Funding Acquisition and Conceptualization, D.R.

Funding: This research was funded by the [Ministry of Economy and Competitiveness, MINECO] and [FEDER] grant number [AGL2013-48993-C2-2-R].

Acknowledgments: The present research work was funded by the Ministry of Economy and Competitiveness and with FEDER funds through project AGL2013-48993-C2-2-R. Maria Consuelo Pina-Pérez is grateful to the Ministry of Economy and Competitiveness (MINECO) for providing a postdoctoral contract under the Juan de la Cierva-Incorporación programme at the Centre of Advanced Food Microbiology, Polytechnic University of Valencia (UPV), Excelencia Profesional de Maestría en Ciencias Agropecuarias SENACYT-IFARHU program, and also to the European Commission for the funds provided to her under the H2020 MSCA programme, reference EU 748314.

Conflicts of Interest: The authors declare no conflict of interest.

\section{References}

1. Miyashita, K.; Mikami, N.; Hosokawa, M. Chemical and nutritional characteristics of brown seaweed lipids: A review. J. Funct. Foods 2013, 5, 1507-1517. [CrossRef]

2. Susanto, E.; Suhaeli Fahmi, A.; Abe, M.; Hosokawa, M.; Miyashita, K. Lipids, fatty acids, and fucoxanthin content from temperate and tropical brown seaweeds. Aquat. Proc. 2016, 7, 66-75. [CrossRef]

3. Wells, M.L.; Potin, P.; Craigie, J.S.; Raven, J.A.; Merchant, S.S.; Helliwell, K.E.; Smith, A.G.; Camire, M.E.; Brawley, S.H. Algae as nutritional and functional food sources: Revisiting our understanding. J. Appl. Phycol. 2017, 29, 949-982. [CrossRef] [PubMed]

4. Peinado, I.; Girón, J.; Koutsidis, G.; Ames, J.M. Chemical composition, antioxidant activity and sensory evaluation of five different species of brown edible seaweeds. Food Res. Int. 2014, 66, 36-44. [CrossRef] 
5. O'Sullivan, L.; Murphy, B.; McLoughlin, P.; Duggan, P.; Lawlor, P.G.; Hughes, H.; Gardiner, G.E. Prebiotics from marine macroalgae for human and animal health applications. Mar. Drugs 2010, 8, 2038-2064. [CrossRef] [PubMed]

6. McCusker, S.; Buff, P.R.; Yu, Z.; Fascetti, A.J. Amino acid content of selected plant, algae and insect species: a search for alternative protein sources for use in pet foods. J. Nutr. Sci. 2014, 3, 1-5. [CrossRef]

7. Qiao, J. Antibacterial effect of extracts from two Icelandic algae (Ascophyllumnodosum and Laminariadigitata). United Nations University, Fisheries Training Programme. 2010, pp. 1-37. Available online: https://pdfs. semanticscholar.org/9224/a0f05bbb3331cf7fa9afbb9e57ecede26c50.pdf (accessed on 22 April 2018).

8. De Jesus Raposo, M.; De Morais, A.; De Morais, R. Marine polysaccharides from algae with potential biomedical applications. Mar. Drugs 2015, 13, 2967-3028. [CrossRef] [PubMed]

9. Moghadamtousi, S.Z.; Karimian, H.; Khanabdali, R.; Razavi, M.; Firoozinia, M.; Zandi, K.; Kadir, H.A. Anticancer and antitumor potential of fucoidan and fucoxanthin, two main metabolites isolated from brown algae. Sci. World J. 2014, 2014, 1-10. [CrossRef] [PubMed]

10. Tutor Ale, M.; Mikkelsen, J.D.; Meyer, A.S. Important determinants for fucoidan bioactivity: A critical review of structure-function relations and extraction methods for fucose-containing sulfated polysaccharides from brown seaweeds. Mar. Drugs 2011, 9, 2106-2130. [CrossRef]

11. Wijesekara, I.; Pangestuti, R.; Kim, S.K. Biological activities and potential health benefits of sulphated polysaccharides derived from marine algae. Carbohydr. Polym. 2011, 84, 14-21. [CrossRef]

12. Choi, S.M.; Jang, E.J.; Cha, J.D. Synergistic effect between fucoidan and antibiotics against clinic methicillin-resistant Staphylococcus aureus. Adv. Biosci. Biotechnol. 2015, 6, 275-285. [CrossRef]

13. Shannon, E.; Abu-Ghannam, N. Antibacterial derivatives of marine algae: An overview of pharmacological mechanisms and applications. Mar. Drugs 2016, 14, 1-23. [CrossRef] [PubMed]

14. Silva, T.H.; Alves, A.; Popa, E.G.; Reys, L.; Gomes, M.E.; Sousa, R.A.; Silva, S.S.; Mano, J.F.; Reis, R.L. Marine algae sulfated polysaccharides for tissue engineering and drug delivery approaches. Biomaterials 2012, 2, 278-289. [CrossRef] [PubMed]

15. Besednova, N.; Zaporozhets, T.; Somova, L.; Kuznetsova, T. Review: Prospects for the use of extracts and polysaccharides from marine algae to prevent and treat the diseases caused by Helicobacter pylori. Helicobacter 2015, 20, 89-97. [CrossRef] [PubMed]

16. Yu, S.H.; Wu, S.J.; Wu, J.Y.; Wen, D.Y.; Mi, F. Preparation of fucoidan-shelled and genipin-crosslinked chitosan beads for antibacterial application. Carbohydr. Polym. 2015, 126, 97-107. [CrossRef] [PubMed]

17. He, F.; Yang, Y.; Yang, G.; Yu, L. Studies on antibacterial activity and antibacterial mechanism of a novel polysaccharide from Streptomyces virginia H03. Food Control 2010, 21, 1257-1262. [CrossRef]

18. Marudhupandi, T.; Thangappan, T.K.A. Antibacterial effect of fucoidan from Sargassum wightii against the chosen human bacterial pathogens. Int. Curr. Pharm. J. 2013, 2, 156-158. [CrossRef]

19. Zhu, Q.; Gooneratne, R.; Altaf Hussain, M. Listeria monocytogenes in fresh produce: Outbreaks, prevalence and contamination levels. Foods 2017, 6, 21. [CrossRef] [PubMed]

20. Sanz-Puig, M.; Pina-Pérez, M.C.; Martínez-López, A.; Rodrigo, D. Escherichia coli O157:H7 and Salmonella typhimurium inactivation by the effect of mandarin, lemon, and orange by-products in reference medium and in oat-fruit juice mixed beverage. LWT-Food Sci. Technol. 2016, 66, 7-14. [CrossRef]

21. Saucedo-Reyes, D.; Marco-Celdrán, A.; Pina-Pérez, M.C.; Rodrigo, D.; Martínez López, A. Modeling survival of high hydrostatic pressure treated stationary and exponential phase Listeria innocua cells. Inn. Food Sci. Emerg. Technol. 2009, 10, 135-141. [CrossRef]

22. Lee, K.Y.; Jeong, M.R.; Choi, S.M.; Na, S.S.; Cha, J. Synergistic effect of fucoidan with antibiotics against oral pathogenic bacteria. Archives Oral Biol. 2013, 58, 482-492. [CrossRef] [PubMed]

23. Hwang, P.A.; Phan, N.N.; Lu, W.J.; Ngoc Hieu, B.T.; Lin, Y.C. Low-molecular-weight fucoidan and high-stability fucoxanthin from brown seaweed exert prebiotics and anti-inflammatory activities in Caco-2 cells. Food Nutr. Res. 2016, 60, 32033. [CrossRef] [PubMed]

24. Lee, I.S.; Slonczewski, J.L.; Foster, J.W. A low-pH-inducible, stationary-phase acid tolerance response in Salmonella typhimurium. J. Bacteriol. 1994, 176, 1422-1426. [CrossRef] [PubMed]

25. Alvarez-Ordóñez, A.; Fernández, A.; Bernardo, A.; López, M. Acid tolerance in Salmonella typhimurium induced by culturing in the presence of organic acids at different growth temperatures. Food Microbiol. 2010, 27, 44-49. [CrossRef] [PubMed] 
26. Gandhi, M.; Chikindas, M. Listeria: A foodborne pathogen that knows how to survive. Int. J. Food Microbiol. 2007, 113, 1-15. [CrossRef] [PubMed]

27. Belda-Galbis, C.M.; Leufvén, A.; Martínez, A.; Rodrigo, D. Predictive microbiology quantification of the antimicrobial effect of carvacrol. J. Food Eng. 2014, 141, 37-43. [CrossRef]

28. Belda-Galbis, C.M.; Jiménez-Carretón, A.; Pina-Pérez, M.C.; Martínez, A.; Rodrigo, D. Antimicrobial activity of açaí against Listeria innocua. Food Control 2015, 53, 212-216. [CrossRef]

29. Moroney, N.C.; O'Grady, M.N.; Lordan, S.; Stanton, C.; Kerry, J.P. Seaweed polysaccharides (laminarin and fucoidan) as functional ingredients in pork meat: An evaluation of anti-oxidative potential, thermal stability and bioaccessibility. Mar. Drugs 2015, 13, 2447-2464. [CrossRef] [PubMed]

30. Ammar, H.H.; Lajili, S.; Said, R.B.; Le Cerf, D.; Bouraoui, A.; Majdoub, H. Physico-chemical characterization and pharmacological evaluation of sulfated polysaccharides from three species of Mediterranean brown algae of the genus Cystoseira. DRAU J. Pharm. Sci. 2015, 23, 1-8. [CrossRef] [PubMed]

31. Rashima, R.S.; Maizura, M.; Kang, W.M.; Fazilah, A.; Tan, L.X. Influence of sodium chloride treatment and polysaccharides as debittering agent on the physicochemical properties, antioxidant capacity and sensory characteristics of bitter gourd (Momordica charantia) juice. J. Food Sci. Technol. 2017, 54, 228-235. [CrossRef] [PubMed]

(C) 2018 by the authors. Licensee MDPI, Basel, Switzerland. This article is an open access article distributed under the terms and conditions of the Creative Commons Attribution (CC BY) license (http:/ / creativecommons.org/licenses/by/4.0/). 